\title{
PENGGUNAAN FUNGSI BLOCK PULSE TERMODIFIKASI UNTUK MENGAPROKSIMASI PERSAMAAN INTEGRAL-DIFERENSIAL VOLTERRA-FREDHOLM LINIER
}

\author{
AYYUBI AHMAD \\ Program Studi Matematika, \\ Fakultas Sains dan Teknologi Terapan, Universitas Ahmad Dahlan, \\ Yogyakarta, Indonesia. \\ e-mail: ayyubiahmad1@gmail.com
}

\author{
Diterima 3 Maret $2021 \quad$ Direvisi 9 Maret $2021 \quad$ Dipublikasikan 29 April 2021
}

\begin{abstract}
Abstrak. Sebuah metode numerik berdasarkan pada fungsi block pulse termodifikasi (FBPT) digunakan untuk menyelesaikan persamaan integral-diferensial VolterraFredholm linier (PI-DV-FL). Kita memperoleh sebuah matriks operasional integrasi dari fungsi block pulse termodifikasi pada interval [0,T). Fungsi block pulse termodifikasi dan matriks operasional integrasinya dapat menyederhanakan persamaan integral-diferensial Volterra-Fredholm linier ke dalam bentuk sistem persamaan linier. Tingkat konvergensi dan analisis galat dari metode yang digunakan diselidiki. Sebuah contoh diberikan untuk menunjukkan bahwa metode yang digunakan memiliki tingkat akurasi yang baik dengan melihat nilai pada tiap titik dan ilustrasi grafiknya.

Kata Kunci: Fungsi Block Pulse Termodifikasi, Matriks Operasional Integrasi, Persamaan Integral-Diferensial Volterra-Fredholm Linier
\end{abstract}

\section{Pendahuluan}

Persamaan integral-diferensial terjadi di beberapa model matematis dari berbagai fenomena dalam bidang matematika, fisika, ekonomi, teknik, dan biologi. Beberapa contoh dari model tersebut dapat ditemukan di literatur dan beberapa masalah teknik, matematika terapan, dan fisika matematika yang disederhanakan ke dalam persamaan integral Volterra-Fredholm. Namun, para peneliti telah menerapkan topik mengenai persamaan integral-diferensial melalui penelitiannya di berbagai bidang seperti neurosains [3], spesies biologis [2], [10], teori airfoil [5], teori antrian [7], masalah kontak elastis [6], [9], mekanisme fraktur [11], dan konduksi molekular [4].

Pada tahun-tahun belakangan ini, beberapa fungsi basis telah digunakan untuk mengestimasi solusi persamaan integral seperti fungsi ortogonal dan wavelet. Pada penelitian ini, kita menggunakan fungsi block pulse termodifikasi untuk mengaproksimasi solusi $f(t)$ dari persamaan integral-diferensial Volterra-Fredholm linier 
berikut

$$
\begin{aligned}
f^{\prime}(t) & =g(t)+\int_{0}^{t} k(t, s) f(s) \mathrm{d} s+\int_{0}^{1} l(t, s) f(s) \mathrm{d} s, \quad 0 \leq t, s<1, \\
f(0) & =a_{0},
\end{aligned}
$$

di mana $f(t)$ dan $g(t)$ masing-masing merupakan fungsi analitik yang tidak diketahui dan diketahui dalam $L^{2}([0,1))$ dan $k(t, s)$ dan $l(t, s)$ merupakan kernel dalam $L^{2}([0,1) \times[0,1))$.

\section{Landasan Teori}

\subsection{Fungsi Block Pulse Termodifikasi}

Suatu himpunan fungsi block pulse termodifikasi $\varepsilon \phi_{i}(t), i=0,1, \cdots, m$ pada interval $[0, T)$ yang didefinisikan sebagai berikut

$$
\begin{gathered}
\phi_{0}(t)= \begin{cases}1, & t \in[0, h-\varepsilon)=I_{0}, \\
0, & \text { yang lainnya, }\end{cases} \\
\phi_{i}(t)= \begin{cases}1, & t \in[i h-\varepsilon,(i+1) h-\varepsilon)=I_{i}, \quad i=1,2, \cdots, n-1, \\
0, & \text { yang lainnya, }\end{cases}
\end{gathered}
$$

dan

$$
\phi_{n}(t)= \begin{cases}1, & t \in[T-\varepsilon, T), \\ 0, & \text { yang lainnya }\end{cases}
$$

di mana $n$ merupakan sebarang bilangan bulat positif dan $h=\frac{T}{n}$.

\subsection{Sifat-sifat Fungsi Block Pulse Termodifikasi}

FBPT memiliki sifat-sifat dasar yang sama seperti fungsi block pulse, antara lain:

(1) Keterpisahan (Disjointness): FBPT terpisah satu sama lain pada interval $t \in$ $[0, T)$,

$$
\phi_{i}(t) \phi_{j}(t)=\left\{\begin{array}{cc}
\phi_{i}(t), & i=j \\
0, & i \neq j
\end{array}\right.
$$

di mana $i, j=0,1, \cdots, n$.

(2) Ortogonalitas (Orthogonality): PFBP ortogonal satu sama lain pada interval $t \in[0, T)$

$$
\int_{0}^{T} \phi_{i}(t) \phi_{j}(t) \mathrm{d} t=h \delta_{i j},
$$

di mana $i, j=1, \cdots, n-1$ dan $\delta_{i j}$ merupakan delta Kronecker. 
(3) Kelengkapan (Completeness): Jika $n \rightarrow \infty$, maka himpunan FBPT adalah lengkap yaitu untuk setiap $f \in L^{2}([0, T))$,

$$
\int_{0}^{T} f^{2}(t) \mathrm{d} t=\sum_{i=0}^{\infty} f_{i}^{2}\left\|\phi_{i}(t)\right\|^{2}
$$

di mana

$$
f_{i}=\frac{1}{\Delta\left(I_{i}\right)} \int_{0}^{T} f(t) \phi_{i}(t) \mathrm{d} t,
$$

dan $\Delta\left(I_{i}\right)$ merupakan panjang interval $I_{i}$.

\subsection{Bentuk Vektor Fungsi Block Pulse Termodifikasi}

Pertama kita mempertimbangkan bentuk $(n+1)$ FBPT dan menulisnya dengan sederhana sebagai vektor- $(n+1)$

$$
\Phi(t)=\left[\phi_{0}(t), \phi_{1}(t), \cdots, \phi_{n}(t)\right]^{T}, \quad t \in I .
$$

Pers. (2.1) berarti bahwa

$$
\Phi(t) \Phi^{T}(t)=\left[\begin{array}{cccc}
\phi_{0}(t) & 0 & \ldots & 0 \\
0 & \phi_{1}(t) & \ldots & 0 \\
\vdots & \vdots & \ddots & \vdots \\
0 & 0 & \ldots & \phi_{n}(t)
\end{array}\right]=\operatorname{diag}(\Phi(t)) .
$$

Sekarang nyatakan bahwa $X$ sebagai vektor- $(n+1)$. Jadi, dengan menggunakan Pers. (2.5) kita peroleh

$$
\Phi(t) \Phi^{T}(t) X=\tilde{X} \Phi(t),
$$

di mana $\tilde{X}=\operatorname{diag}(X)$ merupakan matriks diagonal $(n+1) \times(n+1)$.

\subsection{Perluasan Fungsi Block Pulse Termodifikasi}

Sebuah fungsi kontinu $f(t) \in L^{2}(I)$ dapat diperluas dengan FBPT yaitu

$$
f(t) \simeq f_{n}(t)=\sum_{i=0}^{n} f_{i} \phi_{i}(t)=F^{T} \Phi(t)=\Phi^{T}(t) F,
$$

di mana $F$ adalah vektor- $(n+1) \times 1$ diberikan dengan

$$
F=\left[f_{0}, f_{1}, \cdots, f_{n}\right]^{T} .
$$

Dengan cara yang sama, sebuah fungsi dua variabel $k(t, s) \in L^{2}(I \times I)$ dapat diperluas dengan FBPT sebagai berikut

$$
k(t, s) \simeq k_{n}(t, s)=\Phi^{T}(t) K \Phi(s)=\Phi^{T}(s) K^{T} \Phi(t),
$$

di mana $\Phi(t)$ dan $\Phi(s)$ masing-masing merupakan vektor FBPT dimensi $\left(n_{1}+1\right)$ dan $\left(n_{2}+1\right)$, dan $K=\left(k_{i j}\right), i=0,1, \cdots, n_{1}, j=0,1, \cdots, n_{2}$ merupakan matriks koefisien block pulse termodifikasi $\left(n_{1}+1\right) \times\left(n_{2}+1\right)$ dengan

$$
k_{i j}=\frac{1}{\Delta\left(I_{i}\right) \Delta\left(I_{j}\right)} \int_{0}^{T_{1}} \int_{0}^{T_{2}} k(t, s) \phi_{i}(t) \phi_{j}(s) \mathrm{d} s \mathrm{~d} t .
$$




\subsection{Matriks Operasional Integrasi Fungsi Block Pulse} Termodifikasi

Sama seperti FBP,

$$
\int_{0}^{t} \Phi(s) \mathrm{d} s \simeq Q \Phi(t)
$$

di mana matriks operasional integrasi $Q$ dari FBPT $\varepsilon$ diberikan dengan

$$
Q=\left[\begin{array}{cccc}
\frac{h-\varepsilon}{2} & h-\varepsilon & \ldots & h-\varepsilon \\
0 & \frac{h}{2} & \ldots & h \\
\vdots & \vdots & \ddots & \vdots \\
0 & 0 & \ldots & \frac{\varepsilon}{2}
\end{array}\right]_{(n+1) \times(n+1)}
$$

Jadi, integral setiap fungsi $f(t)$ dapat diaproksimasi sebagai berikut

$$
\int_{0}^{t} f(s) \mathrm{d} s=\int_{0}^{t} F^{T} \Phi(s) \mathrm{d} s \simeq F^{T} Q \Phi(t) .
$$

\section{Hasil dan Pembahasan}

\subsection{Fungsi Block Pulse Termodifikasi dalam Menyelesaikan}

\section{Persamaan Integral-Diferensial Volterra-Fredholm Linier}

Mempertimbangkan persamaan integral-diferensial Volterra-Fredholm linier berikut

$$
\begin{aligned}
f^{\prime}(t) & =g(t)+\int_{0}^{t} k(t, s) f(s) \mathrm{d} s+\int_{0}^{1} l(t, s) f(s) \mathrm{d} s, \quad 0 \leq t, s<1, \\
f(0) & =a_{0} .
\end{aligned}
$$

Pertama, kita integralkan kedua ruas Pers. (3.1) pada interval $[0, T)$, kita akan memiliki

$$
f(t)=a_{0}+\int_{0}^{t} g(u) \mathrm{d} u+\int_{0}^{t} \int_{0}^{u} k(u, s) f(s) \mathrm{d} s \mathrm{~d} u+\int_{0}^{t} \int_{0}^{1} l(u, s) f(s) \mathrm{d} s \mathrm{~d} u .
$$

Kita aproksimasi fungsi $f, g, k$, dan $l$ dengan $\mathrm{FBPT} \varepsilon$ sebagai berikut:

$$
\begin{aligned}
f(t) & \simeq F^{T} \Phi(t)=\Phi^{T}(t) F, \\
g(t) & \simeq \Phi^{T}(t) G, \\
k(t, s) & \simeq \Phi^{T}(t) K \Phi(s), \\
l(t, s) & \simeq \Phi^{T}(t) L \Phi(s),
\end{aligned}
$$

di mana vektor $F$ dan $G$, matriks $K$ dan $L$ masing-masing merupakan koefisien FBPT $\varepsilon$ dari $f, g, k$, dan $l$. Substitusikan Pers. (3.3) ke dalam Pers. (3.2), kita akan memiliki

$$
\begin{aligned}
\Phi^{T}(t) F \simeq & a_{0}+\Phi^{T}(t) P^{T} G+\int_{0}^{t} \Phi^{T}(u) K\left(\int_{0}^{u} \Phi(s) \Phi^{T}(s) F \mathrm{~d} s\right) \mathrm{d} u \\
& +\int_{0}^{t} \Phi^{T}(u) L\left(\int_{0}^{1} \Phi(s) \Phi^{T}(s) \mathrm{d} s\right) F \mathrm{~d} u \\
\simeq & a_{0} \Phi^{T}(t) \Phi(t)+\Phi^{T}(t) P^{T} G+\int_{0}^{t} \Phi^{T}(u) K \tilde{F} P \Phi(u) \mathrm{d} u+h \Phi^{T}(t) P^{T} L F
\end{aligned}
$$


di mana $\tilde{F}=\operatorname{diag}(F)$ dan misalkan $B=K \tilde{F} P$, maka diperoleh

$$
\Phi^{T}(t) F \simeq a_{0} \Phi^{T}(t) \Phi(t)+\Phi^{T}(t) P^{T} G+\Phi^{T}(t) P^{T} \hat{B}+h \Phi^{T}(t) P^{T} L F .
$$

Misalkan $\hat{A}=P^{T} \hat{B}$, kita peroleh

$$
\Phi^{T}(t) F \simeq a_{0} \Phi^{T}(t) \Phi(t)+\Phi^{T}(t) P^{T} G+\Phi^{T}(t) A \Phi(t)+h \Phi^{T}(t) P^{T} L F,
$$

di mana $A=\operatorname{diag}(\hat{A})$. Lalu

$$
\Phi^{T}(t) F \simeq \Phi^{T}(t)\left(a_{0} I+A\right) \Phi(t)+\Phi^{T}(t)\left(P^{T} G+h P^{T} L F\right) .
$$

Mengubah $C=a_{0} I+A$ dan diperoleh

$$
\begin{aligned}
\Phi^{T}(t) F & \simeq \Phi^{T}(t) C \Phi(t)+\Phi^{T}(t)\left(P^{T} G+h P^{T} L F\right) \\
F & \simeq \hat{C}+P^{T} G+h P^{T} L F,
\end{aligned}
$$

di mana $\hat{C}=a_{0} \mathbf{1}+h^{2} K^{\prime} F$ dengan $\mathbf{1}=[1,1, \cdots, 1]^{T}$ dan

$$
K^{\prime}=\left[\begin{array}{cccc}
\frac{1}{4} k_{00} & 0 & \ldots & 0 \\
\sum_{i=0}^{1}{ }^{\prime \prime} k_{i 0} & \frac{1}{4} k_{11} & \ldots & 0 \\
\vdots & \vdots & \ddots & \vdots \\
\sum_{i=0}^{n}{ }^{\prime \prime} k_{i 0} & \sum_{i=0}^{n}{ }^{\prime \prime} k_{i 1} & \ldots & \frac{1}{4} k_{n n}
\end{array}\right],
$$

dan $\sum^{\prime \prime}$ berarti bahwa pola pertama dan terakhir memiliki faktor $\frac{1}{2}$. Kemudian,

$$
\begin{aligned}
F-h P^{T} L F-\hat{C} & =P^{T} G \\
F-h P^{T} L F-a_{0} \mathbf{1}-h^{2} K^{\prime} F & =P^{T} G \\
F-h P^{T} L F-h^{2} K^{\prime} F & =P^{T} G+a_{0} \mathbf{1} \\
\left(I-h P^{T} L-h^{2} K^{\prime}\right) F & =P^{T} G+a_{0} \mathbf{1} \\
F & =\left(I-h P^{T} L-h^{2} K^{\prime}\right)^{-1}\left(P^{T} G+a_{0} \mathbf{1}\right) .
\end{aligned}
$$

Dalam menyelesaikan sistem persamaan (3.4), kita memperoleh $f_{0}, f_{1}, \cdots, f_{n}$ yang tidak diketahui.

\subsection{Analisis Galat}

Teorema 3.1. Nyatakan $f$ kontinu pada I dan terdiferensial pada $[0,1)$ serta terdapat bilangan $M$ yaitu $\left|f^{\prime}(t)\right| \leq M$, untuk setiap $t \in I$, maka

$$
|f(b)-f(a)| \leq M|b-a|,
$$

untuk setiap $a, b \in I$.

Bukti. Lihat [1].

Teorema 3.2. Asumsikan bahwa $f(t)$ merupakan fungsi terdiferensial pada I yaitu $\left|f^{\prime}(t)\right| \leq M$. Kita mendefinisikan galat antara $f(t)$ dan perluasan FBPT atas setiap subinterval $I_{i}$ sebagai berikut:

$$
e_{i}(t)=f_{i}-f(t), \quad t \in I_{i},
$$


di mana $I_{i}=\left[\frac{i}{n}, \frac{i+1}{n}\right)$.

Bukti. Hal ini dapat ditunjukkan bahwa

$$
\begin{aligned}
\left\|e_{i}\right\|^{2} & =\int_{\frac{i}{n}}^{\frac{i+1}{n}} e_{i}^{2}(t) \mathrm{d} t \\
& =\int_{\frac{i}{n}}^{\frac{i+1}{n}}\left(f_{i}-f(t)\right)^{2} \mathrm{~d} t \\
& =\frac{1}{n}\left(f_{i}-f(\eta)\right)^{2}, \quad \eta \in I_{i},
\end{aligned}
$$

di mana digunakan teorema nilai rata-rata untuk integral. Dengan menggunakan Pers. (2.3) dan teorema nilai rata-rata, diperoleh:

$$
f_{i}=n \int_{\frac{i}{n}}^{\frac{i+1}{n}} f(t) \mathrm{d} t=n \frac{1}{n} f(\xi)=f(\xi), \quad \xi \in I_{i} .
$$

Substitusikan (3.6) ke dalam (3.5), diperoleh:

$$
\left\|e_{i}\right\|^{2}=\frac{1}{n}(f(\xi)-f(\eta))^{2} \leq \frac{M^{2}}{n}|\xi-\eta|^{2} \leq \frac{M^{2}}{n^{3}} .
$$

Ini mengarah ke:

$$
\begin{aligned}
\|e(t)\|^{2} & =\int_{0}^{1} e^{2}(t) \mathrm{d} t \\
& =\int_{0}^{1}\left(\sum_{i=0}^{n} e_{i}(t)\right)^{2} \mathrm{~d} t \\
& =\int_{0}^{1}\left(\sum_{i=0}^{n} e_{i}^{2}(t)\right) \mathrm{d} t+2 \sum_{i \leq j} \int_{0}^{1} e_{i}(t) e_{j}(t) \mathrm{d} t .
\end{aligned}
$$

Karena $i \neq j, I_{i} \cap I_{j}=\oslash$, maka

$$
\|e(t)\|^{2}=\sum_{i=0}^{n}\left(\int_{0}^{1} e_{i}^{2}(t) \mathrm{d} t\right)=\sum_{i=0}^{n}\left\|e_{i}\right\|^{2} .
$$

Substitusikan (3.7) ke dalam (3.8), diperoleh:

$$
\|e(t)\|^{2} \leq \frac{M^{2}}{n^{2}}
$$

Jadi, $\|e(t)\|=\mathcal{O}\left(\frac{1}{n}\right)$, di mana $e(t)=f_{n}(t)-f(t)$ dan $f_{n}(t)=\sum_{i=0}^{n} f_{i} \phi_{i}(t)$.

\subsection{Contoh Numerik}

Pandang persamaan integral-diferensial Volterra-Fredholm linier berikut [8]:

$$
\begin{aligned}
f^{\prime}(t)= & -2 \sin (t)-t^{2} \sin (2 t)+2 \sin (2 t)-2 t \cos (2 t)-2 e^{t}+5 e^{t-1}+2 t \\
& +\int_{0}^{t} \cos (t+s) f(s) \mathrm{d} s+\int_{0}^{1} e^{t-s} f(s) \mathrm{d} s, \\
f(0)= & 0,
\end{aligned}
$$


dengan solusi eksak $f(t)=t^{2}$.

Tabel 1. Solusi Eksak dan Aproksimasi

\begin{tabular}{|c|c|c|}
\hline$t$ & Eksak & Aproksimasi \\
\hline 0 & 0 & 0 \\
\hline 0.1 & 0.01 & 0.01197 \\
\hline 0.2 & 0.04 & 0.04355 \\
\hline 0.3 & 0.09 & 0.09442 \\
\hline 0.4 & 0.16 & 0.1643 \\
\hline 0.5 & 0.25 & 0.2529 \\
\hline 0.6 & 0.36 & 0.3602 \\
\hline 0.7 & 0.49 & 0.4866 \\
\hline 0.8 & 0.64 & 0.6329 \\
\hline 0.9 & 0.81 & 0.8008 \\
\hline 1 & 1 & 0.9849 \\
\hline
\end{tabular}

\section{Kesimpulan}

Fungsi block pulse termodifikasi dan matriks operasional integrasinya digunakan untuk memperoleh solusi persamaan integral-diferensial Volterra-Fredholm linier. Tingkat konvergensi dan akurasi dari metode diselidiki pada sebuah contoh. Hasil menunjukkan bahwa nilai pada setiap titik dari solusi eksak dan aproksimasi memiliki selisih yang sangat kecil. Kedua hasil menunjukkan metode yang digunakan memiliki efisiensi dan akurasi yang baik.

\section{Daftar Pustaka}

[1] Bartle, R. G., 1976, The Elements of Real Analysis, Second Edition, John Wiley and Sons, USA.

[2] Basirat, B., Maleknejad, K., Hashemizadeh, E., 2012, Operational Matrix Approach for the Nonlinear Volterra-Fredholm Integral Equations: Arising in Physics and Engineering, Int. J. Phys. Sci., Volume 7: 226 - 233.

[3] Delves, L. M., Mohamed, J. L., 1985, Computational Methods for Integral Equations, Cambridge University Press, Cambridge, UK.

[4] Frankel, J., 1995, A Galerkin Solution to Regularized Cauchy Singular IntegroDifferential Equation, Q. Appl. Math., Volume 52: 145 - 258.

[5] Golberg, M. A., 1984, The Convergence of a Collocations Method for a Class of Cauchy Singular Integral Equations, J. Math. Appl., Volume 100: 500 - 512.

[6] Kovalenko, E. V., 1989, Some Approximate Methods for Solving Integral Equations of Mixed Problems, Probl. Math. Mech., Volume 53: 85 - 92.

[7] Polyanin, A. D., Manzhirov, A. V., 2008, Handbook of Integral Equations, 2nd ed., Chapman and Hall/CRC Press, London, UK.

[8] Rahmani, L., Rahimi, B., Mordad, M., 2011, Numerical Solution of VolterraFredholm Integro-Differential Equation by Block Pulse Functions and Operational Matrices, Gen. Math. Notes, Volume 4: $37-48$. 
[9] Semetanian, B. J., 1991, On An Integral Equation for Axially Symmetric Problem in the Case of An Elastic Body Containing An Inclusion, J. Appl. Math. Mech., Volume 55: $371-375$.

[10] Wazwaz, A. M., 1997, A First Course in Integral Equations, World Scientific, Singapore.

[11] Willis, J. R., Nemat-Nasser, S., 1990, Singular Perturbation Solution of a Class of Singular Integral Equations, Quart. Appl. Math., Volume XLVIII: $741-753$. 